\title{
Evaluation of Pesticide Residues in Human Blood Samples of Agro Professionals and Non-Agro Professionals
}

\author{
Yawar Latif, Syed Tufail Hussain Sherazi*, Muhammad Iqbal Bhanger, Shafi Nizamani \\ National Centre of Excellence in Analytical Chemistry, University of Sindh, Jamshoro, Pakistan \\ Email: tufail.sherazi@yahoo.com
}

Received April 2, 2012; revised May 21, 2012; accepted June 11, 2012

\begin{abstract}
The aim of the present study was to evaluate the pesticide residues in human blood samples of volunteers related to Hyderabad and Mirpurkhas districts, Pakistan. The volunteers of both districts were divided into four groups on the basis of their exposure period to pesticides i.e. Group A -5 to 9 years, Group B-10 to 14 years, Group C -15 to 19 years and Group D-above 20 years. Out of total 188 volunteers, 145 volunteers $(77.1 \%)$ were agro professionals and 43 volunteers (32.9\%) were non-agro professionals. Chlorpyrifos, endosulfan, 1,1,1-trichloro-2,2-bis (p-chorophenyl) ethane $\left(p, p^{\prime}\right.$-DDT) and parathion residues were detected in many samples. The predominant pesticides found in blood samples of both district volunteers were chlorpyrifos (with highest mean concentration of $0.37 \mathrm{mg} \cdot \mathrm{kg}^{-1}$ in the D group of Mirpurkhas) and endosulfan (with highest mean concentration of $0.30 \mathrm{mg} \cdot \mathrm{kg}^{-1}$ in the D group of Hyderabad). The quantity of pesticide residues detected in some blood samples of agro professionals was found to be at the alarming level.
\end{abstract}

Keywords: Pesticides; Exposure to Population; Blood Samples

\section{Introduction}

Many types of insecticides, fungicides and herbicides are usually used by the farmers to protect their crops from pests. Controlled pesticide application is an important factor that allows protection of foods from the chemical toxicity. The presence of pesticide residues was already quoted in the blood, urine, semen, breast milk, infant and umbilical cord of human being [1]. Presently, pesticide spray is global concern due to their potential risks to the health of the community [2,3]. Because of successive pesticide application and their high toxicity, numerous cases of fatal poisoning by accidental ingestion and suicidal ingestion or homicidal rationales were reported. Indications of acute poisoning may develop during or after the period of exposure, depending on the type of pesticides and the manner of contact. Pesticides usually disturb the physiological and biochemical activities of lymphocytes and erythrocytes [4]. Also it has been reported that such residues persist in adipose tissues for long periods up to many decades, found to be endocrine disrupters; inhibit many enzymes, cause immune suppression and go ahead to higher susceptibility to beginning of cancer [5-7].

In Pakistan, about $70 \%$ of the population involved in agriculture sector directly or indirectly is lived in villages. To protect the crops from pests attack, farmers use syn-

\footnotetext{
${ }^{*}$ Corresponding author.
}

thetic pesticides and their tendency is increasing day by day [8]. In Pakistan, utilization of pesticides are not well controlled as compared to the developed countries due to ineffective legislation, deficient in awareness about the dangerous outcomes and technical know-how along with the agricultural community, pesticide administration is not being appropriately regulated $[9,10]$. Thus, due to mishandling and malpractices as the spray workers do not follow the necessary precautions, dangerous consquences may occur in their own health and causing various troubles such as pesticide contamination to the food chain and pesticide residue accumulation in the consumer's body. The direction of tolerances including maximum residue level (MRL), acceptable daily intake (ADI) and no observable adverse effect level (NOAEL) for different pesticides in foodstuffs report by Codex Alimentarius Commission [11]. In Pakistan, limited studies have been carried out on pesticide residues in human blood, and urine [12]. The aim of the present study was to evaluate pesticide residues in blood samples of some volunteers of selected rural areas that were either directly or indirectly exposed to pesticides.

\section{Materials and Methods}

\subsection{Selection and Description of Sampling Population}

Selection of areas was based on the higher pesticide 
consumption and extensive agriculture production of numerous commodities. Before taking the blood samples from the volunteers, interviews were conducted with reference to their occupational histories to get knowledge about their years of involvement to pesticide exposure, age, sex and clinical history.

\subsection{Sample Collection}

The samples of blood were collected from 188 volunteers out of which 110 were related to Hyderabad district and remaining 78 were from Mirpurkhas district. The volunteers were categorized into two main groups on the basis of their occupation i.e. Group 1 Agro professionals, those who were involved in farming practices such as spraying activity, growing and harvesting of commodities and Group 2 non-agro professionals, those who were not involved in any farming practices but belong to other profession such as shopkeeper, barber, students, school teachers, housewives etc. The detail of volunteers is described in Table 1. Blood samples $(5 \mathrm{cc}$ ) were collected by butterfly syringe from the veins in the inner forearms of each volunteer. Whole blood was kept in decontaminated labeled glass vials, preserved in an ice box and transported to the laboratory for analysis.

\subsection{Reagents}

Reference standards of pesticides were purchased from Sigma-Aldrich (Germany) with purity between 98\% 99\%. Acetone, dichloromethane, n-hexane were obtained from Sharlau (Barcelona, Spain) and anhydrous sodium sulfate was acquired from Merck (Germany). Stock solutions of each pesticide standard with concentration of $100 \mathrm{mg} / \mathrm{kg}$ were prepared in $\mathrm{n}$-hexane and stored in a freezer at $-18^{\circ} \mathrm{C}$. A mixture from stock solution of all pesticide standards was prepared by transferring $1 \mathrm{ml}$ of each stock solution to a $100 \mathrm{ml}$ volumetric flask and diluted up to the mark with $\mathrm{n}$-hexane $\left(5 \mathrm{mg} \cdot \mathrm{kg}^{-1}\right)$.

\subsection{Extraction and Cleanup}

Extraction of pesticide residues from the whole blood was done according to the reported method [13] with the addition of ultrasonic assistance. According to the procedure $1 \mathrm{ml}$ of methanol and $2 \mathrm{ml}$ of blood sample was taken in $20 \mathrm{ml}$ screw capped vial. Extraction of pesticides was carried out with $10 \mathrm{ml}$ of solvent system containing n-hexane and acetone in the ratio of 9:1. The mixture was shaken for $1 \mathrm{~min}$ on vortex mixer. After addition of anhydrous sodium sulfate the vial was placed in an ultrasonic bath for $2 \mathrm{~min}$, and then centrifuged at 3000 RPM for $5 \mathrm{~min}$. The cleanup procedure was carried out using solid phase extraction (SPE) cartridge containing octadecyl $\left(\mathrm{C}_{18}\right)$ resin. Gradient system was used to elute pesticides initially with $6 \mathrm{ml}$ of pure n-hexane and
Table 1. Number of non-agro professional volunteers who have detected pesticide residues in their blood samples.

\begin{tabular}{cccc}
\hline Location & $\begin{array}{c}\text { No. of volunteers } \\
\text { assessed }\end{array}$ & $\begin{array}{c}\text { No. with residues } \\
\text { detected }\end{array}$ & Proportion (\%) \\
\hline Hyderabad & 27 & 09 & 33.3 \\
Mirpurkhas & 16 & 04 & 25 \\
\hline
\end{tabular}

then with $6 \mathrm{ml}$ of a mixture of n-hexane and dichloromethane in the ratio of $5: 1$. The combined eluates were concentrated under the gentle stream of nitrogen, and an aliquot of the final concentrated extract was analyzed by GC- $\mu$ ECD and GC-MS, respectively.

\subsection{Instrumentation}

Agilent GC system model 7890 A (CA, USA) in combination with micro electron capture detector ( $\mu \mathrm{ECD})$, automatic split-splitless injector model Agilent 7683 B and 7683 Agilent Autosampler was used for the analysis of pesticide residues. For the separation of pesticide residues a HP-5 capillary column supplied by Agilent Technologies with specifications $30 \mathrm{~m} \times 0.32 \mathrm{~mm} \times$ i.d., $0.25 \mu \mathrm{m}$ film thickness, was employed.

For the confirmation of pesticide residues in blood samples, Agilent technologies 6890N series GC system with Agilent 7683 automatic split-splitless injector, interfaced to Agilent 5975 mass spectrometer detector (MSD) in Electron Impact (EI) ionization mode was employed. A capillary column HP-5MS with specifications $30 \mathrm{~m} \times 0.25 \mathrm{~mm} \times$ i.d., $0.25 \mu \mathrm{m}$ film width provided by Agilent technologies, was used. An ultrasonic bath (Raypa-Barcelona, Spain) was used for ultrasonic assisted extraction.

\subsection{Instrumental Conditions}

The operating conditions for GC- $\mu \mathrm{ECD}$ were as follows: The temperature of injection port was $250^{\circ} \mathrm{C}$, injection volume $2 \mu \mathrm{l}$ in split ratio 50:1 and split flow $60 \mathrm{ml} / \mathrm{min}$. The detector temperature was $310^{\circ} \mathrm{C}$. Column temperature was programmed as, the first temperature $70^{\circ} \mathrm{C}$ for 0 $\min$, after that increased at a rate of $30^{\circ} \mathrm{C} / \mathrm{min}$ to $210^{\circ} \mathrm{C}$ and seized for $2 \mathrm{~min}$, then from $210^{\circ} \mathrm{C}$ to $250^{\circ} \mathrm{C}$ at a rate of $25^{\circ} \mathrm{C} / \mathrm{min}$ with held for $2 \mathrm{~min}$, then increased up to $290^{\circ} \mathrm{C}$ with the rate of $30^{\circ} \mathrm{C} / \mathrm{min}$ and finally held for 5 min. The carrier gas, Nitrogen (purity 99.99\%) at a flow rate of $1.2 \mathrm{ml} / \mathrm{min}$ was used. The whole analysis time is less than $17 \mathrm{~min}$, and the time for the equilibration of the system was put $0.5 \mathrm{~min}$.

For GC-MS confirmation the working conditions were as: The temperature for injector port was $250^{\circ} \mathrm{C}$, volume of injection was $2 \mu \mathrm{l}$ in splitless manner, helium (99.99\%) used as carrier gas at $1.2 \mathrm{ml} / \mathrm{min}$ flow rate. For column the temperature program was the same as in GC- $\mu \mathrm{ECD}$. The MSD was run in electron impact ionization manner 
$(I . E=70 \mathrm{eV})$ scanning as from $\mathrm{m} / \mathrm{z} 50$ to 550 at 4.4 $\mathrm{scan} / \mathrm{s}$. Temperatures of ionization source and quadrupole were adjusted at $230^{\circ} \mathrm{C}$ and $150^{\circ} \mathrm{C}$, respectively.

\section{Results and Discussion}

The method was evaluated under the optimized conditions by determining the limits of detection (LOD), quantitation (LOQ). The LODs of each pesticide were calculated at a signal-to-signal ratio of 3 , whereas the limits of LOQs were obtained at a signal-to-signal ration of 10 , as shown in Table 2. For the linearity, blank blood samples fortified with $0.05,0.10$ to $0.20 \mathrm{mg} \cdot \mathrm{kg}^{-1}$ of each pesticide and individual standards of targeted pesticides were run in to the GC- $\mu$ ECD and GC-MS. All of the studied compounds can be identified by their main ions, in the PEST library. Areas under the peak versus concentrations were plotted and fit by simple linear regression to obtain the equation for the standard curves to measure the unknown quantity of pesticides. The amount of each pesticide in each sample was thus calculated based on the slope of the standard curve. Response of the detector was found to be linear with excellent determination coefficient $\mathrm{r} 2 \geq$ 0.9995 for all pesticides. Calibration data have been summarized in Table 2.

Table 2. Calibration data, retention times $\left(t_{R}\right)$, limits of detection (LOD) and limits of quantification (LOQ) in mg $\mathrm{kg}^{-1} \mathrm{of}$ pesticides analyzed by GC- $\mu$ ECD.

\begin{tabular}{|c|c|c|c|c|c|c|}
\hline \multirow{3}{*}{$\begin{array}{l}\# \\
01\end{array}$} & \multirow{3}{*}{$\begin{array}{c}\text { Pesticide } \\
\text { Dichlorvos }\end{array}$} & \multirow{3}{*}{$\begin{array}{r}\mathbf{t}_{\mathbf{R}}, \mathbf{m i n} \\
4.29\end{array}$} & \multicolumn{2}{|c|}{ Calibration Data } & \multirow{2}{*}{\multicolumn{2}{|c|}{$\begin{array}{l}\text { LOD } \\
\left(\mathrm{mg} \cdot \mathrm{kg}^{-1}\right)\end{array}$}} \\
\hline & & & \multirow{2}{*}{$\begin{array}{c}\text { Equation } \\
y=9.5753 x+1.6977\end{array}$} & \multirow{2}{*}{$\frac{\mathbf{R}^{2}}{0.9998}$} & & \\
\hline & & & & & 0.0015 & 0.005 \\
\hline 02 & Phosdrin & 5.08 & $y=6.1418 x+5 \times 10^{-3}$ & 0.9995 & 0.0427 & 0.1407 \\
\hline 03 & $\alpha-\mathrm{HCH}$ & 6.68 & $y=5.075 x+2.5952$ & 0.9997 & 0.0009 & 0.0032 \\
\hline 04 & Dimethoate & 6.82 & $y=11.388 x+1.682$ & 0.9994 & 0.0017 & 0.0058 \\
\hline 05 & $\beta$-HCH & 7.00 & $y=1.5534 x+1.1034$ & 0.9998 & 0.0024 & 0.0083 \\
\hline 06 & $\gamma-\mathrm{HCH}$ & 7.10 & $y=5.1582 x+3.3399$ & 0.99 & 0.0012 & 0.0042 \\
\hline 07 & Disulfoton & 7.30 & $\mathrm{y}=4.3971 \mathrm{x}+4 \times 10^{-4}$ & 0.99 & 0.0126 & 0.0425 \\
\hline 08 & $\delta$ - $\mathrm{HCH}$ & 7.38 & $y=4.2158 x+2.7238$ & 0.9996 & 0.0001 & 0.0032 \\
\hline 09 & Chlorpyrifos Methyl & 7.65 & $y=14.759 x+4.8829$ & 0.9999 & 0.0006 & 0.0021 \\
\hline 10 & Propanil & 7.69 & $y=10.92 x+2.4567$ & 0.9998 & 0.0016 & 0.0064 \\
\hline 11 & Metribuzin & 7.74 & $y=6.7901 x+2.8332$ & 0.9993 & 0.0008 & 0.0027 \\
\hline 12 & Parathion Methyl & 7.85 & $y=13.005 x+2.8897$ & 0.9994 & 0.0009 & 0.0028 \\
\hline 13 & Heptachlor & 7.99 & $y=16.436 x+9.1816$ & 0.999 & 0.0002 & 0.0008 \\
\hline 14 & Bromacil & 8.18 & $y=15.081 x+4.8706$ & 0.9999 & 0.0005 & 0.0019 \\
\hline 15 & Malathion & 8.24 & $y=10.136 x+1.5545$ & 0.9997 & 0.0017 & 0.0058 \\
\hline 16 & Parathion & 8.39 & $y=6.1765 x+4.3059$ & 0.9997 & 0.0007 & 0.0027 \\
\hline 17 & Aldrin & 8.40 & $y=15.002 x+11.291$ & 0.9997 & 0.0003 & 0.001 \\
\hline 18 & Chlorpyrifos & 8.41 & $y=9.4448 x+2.3975$ & 0.9998 & 0.0019 & 0.0061 \\
\hline 19 & Triademofen & 8.44 & $y=8.8255 x+7.165$ & 0.9998 & 0.0071 & 0.0231 \\
\hline 20 & Bromophos Methyl & 8.65 & $y=16.011 x+4.3919$ & 0.9998 & 0.0006 & 0.002 \\
\hline 21 & Allethrin & 8.86 & $y=13.786 x+5.9197$ & 0.9996 & 0.0005 & 0.0017 \\
\hline 22 & Tolyfluanid & 8.89 & $y=16.603 x+9.4754$ & 0.9999 & 0.0004 & 0.0008 \\
\hline 23 & Captan & 8.98 & $y=8.4931 x+4.1676$ & 0.9997 & 0.0005 & 0.002 \\
\hline 24 & Bromophos Ethyl & 9.19 & $y=16.509 x+6.0949$ & 0.9998 & 0.0005 & 0.002 \\
\hline 25 & $\alpha$-Endosulfan & 9.44 & $y=10.839 x+6.6558$ & 0.9995 & 0.0004 & 0.0018 \\
\hline 26 & Dieldrin & 9.83 & $y=2.6265 x-6 \times 10^{-4}$ & 0.9997 & 0.0192 & 0.0642 \\
\hline 27 & $\beta$-Endosulfan & 10.37 & $\mathrm{y}=4.5629 \mathrm{x}+3.1647$ & 0.9996 & 0.0004 & 0.0018 \\
\hline 28 & DDT & 11.00 & $y=15.357 x+7.3635$ & 0.9997 & 0.0038 & 0.0127 \\
\hline 29 & Endosulfan sulfate & 11.01 & $y=14.443 x+7.7363$ & 0.9998 & 0.0003 & 0.0012 \\
\hline 30 & Dialifos & 12.73 & $\mathrm{y}=5.5514 \mathrm{x}+4 \times 10^{-4}$ & 0.9994 & 0.0074 & 0.0262 \\
\hline
\end{tabular}


Detail about the total number of volunteers containing the region, sex, male to female ratio and their mean ages are shown in Figure 1. Out of 110 volunteers from Hyderabad district, 83 were agro professionals (in which males and females were 61 and 22, respectively) and 27 were non-agro professionals (in which 18 were males and 9 were females). The mean age of volunteers from the Hyderabad district was 26.68 years with standard deviation (S.D) of 10.6. Blood samples of 78 volunteers belong to Mirpurkhas district were assessed, out of which 62 were agro professionals (48 males and 14 females) and 16 volunteers were non-agro professionals (13 were males and 3 were females). The mean age of volunteers from Mirpurkhas district was $25.34 \pm 5.8$.

To simplify the data analysis, volunteers of agro professional were further categorized according to their exposure period in farming activities i.e., Group $\mathrm{A}-5$ to 9 years, Group B-10 to 14 years, Group $C-15$ to 19 years and Group D-above 20 years. The detail of agro professional volunteers, their exposure duration, percentages of classified groups with respect to total volunteers and proportions of residues detected in their blood samples is shown in Figure 2. Out of total 83 agro professional volunteers from the Hyderabad district, pesticide residues were detected in $59(71.1 \%)$ volunteers. A comparatively high percentage $(47.4 \%)$ was found in volunteers of the $\mathrm{C}$ group from the Hyderabad district who have detected residues in their blood samples, following $28.8 \%$ and $15.2 \%$ in D and B groups, respectively. While $8.5 \%$ volunteers were members of group $A$ in which pesticide residues were detected. Similarly, out of total 62 agro professional volunteers from the Mirpurkhas district, 45 volunteers $(72.6 \%)$ were found to be contained pesticide residues in their blood samples. A relatively high percentage $(55.5 \%)$ was found in the group $\mathrm{C}$ of Mirpurkhas district who have detected pesticide residues in their blood samples, following $24.4 \%$ and $13.3 \%$ in the B and
D groups, respectively. Only $6.6 \%$ volunteers belonged to the A group was found to be contaminated their blood samples with pesticide residues.

Table 1 shows that out of total 27 non-agro professional volunteers from Hyderabad district, 9 volunteers $(33.3 \%)$ were contained pesticide residues in their blood samples. Similarly, out of total 16 non-agro professional volunteers from Mirpurkhas district, 4 volunteers (25\%) were found to be positive for pesticide residues in their blood samples.

Data in Table 3 illustrates the number of residue detected in agro professional volunteers with their years of exposure, and mean concentrations of pesticide residues found in their blood samples. In 59\% volunteers from the Hyderabad district, the residues of chlorpyrifos were detected in their blood samples with the highest mean concentration of $0.29 \mathrm{mg} \cdot \mathrm{kg}^{-1}$ in group D; while, residues of endosulfan, parathion and $p, p^{\prime}-D D T$ were found in 34\%, $5 \%$ and $2 \%$ volunteers with the mean concentrations of $0.3,0.15$ and $0.17 \mathrm{mg} \cdot \mathrm{kg}^{-1}$, respectively. Residues of parathion and $p, p^{\prime}-D D T$ were not detected in the blood samples of volunteers belonged to the A group. Similarly,

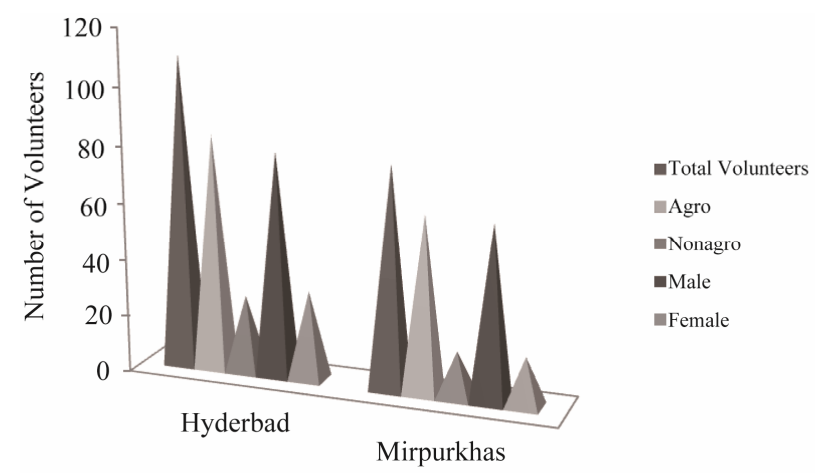

Figure 1. Total number of volunteers, male and female members, agro and non-ngro professionals from Hyderabad and Mirpurkhas districts.

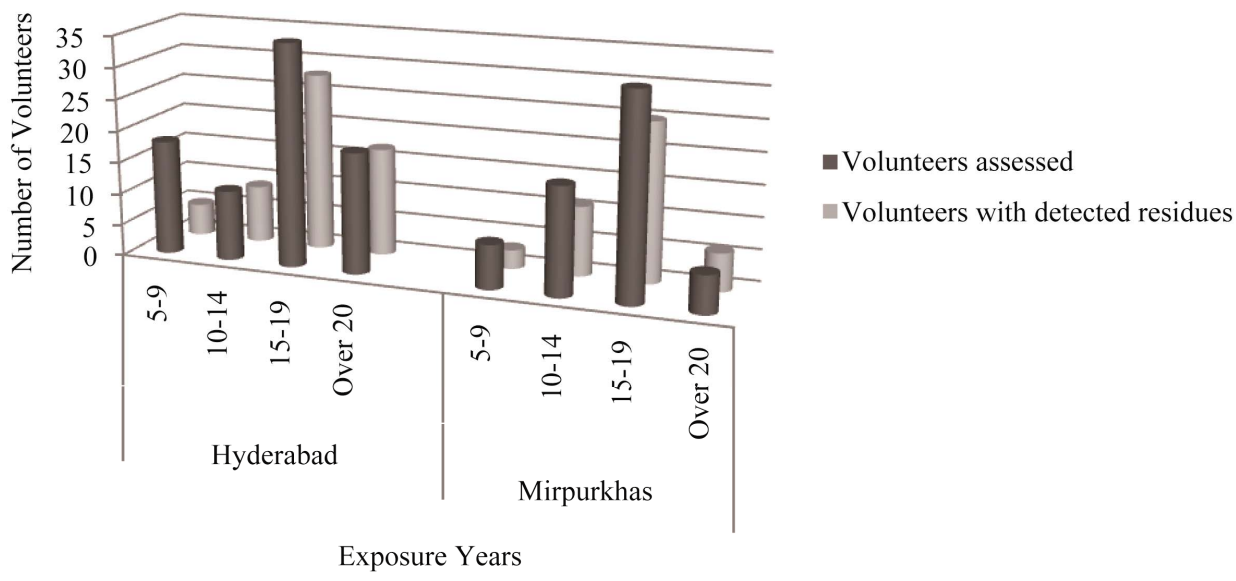

Figure 2. Total number of volunteers assessed and volunteers with detected pesticides residues on the basis of their blood samples in which pesticide residues were detected with their exposure years. 
Table 3. Number of residue detected agro professional volunteers with their years of exposure, and mean concentrations of pesticide residues found in their blood samples.

\begin{tabular}{ccccccc}
\hline \multirow{2}{*}{ Location } & \multirow{2}{*}{$\begin{array}{c}\text { Exposure duration } \\
\text { (years) }\end{array}$} & \multirow{2}{*}{$\begin{array}{c}\text { No. with residues } \\
\text { detected }\end{array}$} & \multicolumn{3}{c}{ Number of volunteers ( ${ }^{*}$ mean pesticide concentration, $\left.\mathrm{mg}^{\mathrm{kg}} \mathrm{kg}^{-1}\right)$} \\
\cline { 5 - 7 } Hyderabad & (A) $5-9$ & 05 & $03(0.07)$ & $02(0.17)$ & $00(0.0)$ & $00(0.0)$ \\
& (B) $10-14$ & 09 & $05(0.11)$ & $03(0.26)$ & $00(0.0)$ & $01(0.15)$ \\
& (C) $15-19$ & 28 & $15(0.18)$ & $11(0.15)$ & $00(0.0)$ & $02(0.13)$ \\
& (D) Over 20 & 17 & $12(0.29)$ & $04(0.30)$ & $01(0.17)$ & $00(0.0)$ \\
Mirpurkhas & (A) $5-9$ & 03 & $01(0.10)$ & $02(0.15)$ & $00(0.0)$ & $00(0.0)$ \\
& (B) $10-14$ & 11 & $07(0.28)$ & $03(0.21)$ & $00(0.0)$ & $01(0.16)$ \\
& (C) $15-19$ & 25 & $12(0.25)$ & $09(0.29)$ & $01(0.20)$ & $03(0.24)$ \\
& (D) Over 20 & 06 & $03(0.37)$ & $02(0.16)$ & $01(0.14)$ & $01(0.31)$ \\
\hline
\end{tabular}

${ }^{*}$ Standard deviation was below $5 \%$ from three replicate analyses of pesticide residues in the analyzed blood samples.

volunteers in the $\mathrm{B}$ and $\mathrm{C}$ groups had not detected residues of $p, p$ '-DDT in their blood samples. Furthermore, in group D of Hyderabad district no any volunteer was found to be contaminated with residues of parathion in their blood samples. Out of total 45 agro professional volunteers from Mirpurkhas district, 51\% had residues of chlorpyrifos, and $36 \%$ had detected endosulfan residues in their blood samples with mean concentrations of 0.37 and $0.29 \mathrm{mg} \cdot \mathrm{kg}^{-1}$, respectively. While, residues of parathion and $p, p \cdot-D D T$ were detected in about $11 \%$ and $5 \%$ of the volunteers with mean concentrations of 0.31 and $0.20 \mathrm{mg} \cdot \mathrm{kg}^{-1}$, respectively. Volunteers of group A and B belonging to Mirpurkhas district, were not shown any residues of $p, p$ '-DDT in their blood samples. Whereas, residues of parathion were also not detected in the blood samples of volunteers belonged to group A of Mirpurkhas district.

Table 4 shows out of total 9 non-agro professional volunteers from the Hyderabad district, 5 volunteers $(55 \%)$ had residues of chlorpyrifos and in 4 volunteers (45\%) were detected for endosulfan residues with mean concentrations of 0.1 and $0.14 \mathrm{mg} \cdot \mathrm{kg}^{-1}$, respectively. From Mirpurkhas district, out of 4 non-agro professional volunteers, 2 volunteers $(50 \%)$ were found to be positive for chlorpyrifos residues with a mean concentration of $0.08 \mathrm{mg} \cdot \mathrm{kg}^{-1}$ in their blood samples. From the remaining 2 volunteers, 1 volunteer had residues of endosulfan and other had residues of $p, p^{\prime}-D D T$ with concentrations of 0.11 and $0.06 \mathrm{mg} \cdot \mathrm{kg}^{-1}$, respectively.

Table 5 shows mean concentrations and ranges of detected pesticide residues based on the gender of agro professional volunteers. According to the results, out of total 35 volunteers who had residues of chlorpyrifos from the Hyderabad district, 28 volunteers $(80 \%)$ were males with ages between 16 to 45 years, $(20 \%)$ were females of ages between 22 to 51 years containing mean concentrations of $0.17 \mathrm{mg} \cdot \mathrm{kg}^{-1}$ and $0.15 \mathrm{mg} \cdot \mathrm{kg}^{-1}$, respectively. The blood samples of 11 male volunteers $(55 \%)$ out of total
20 were found to be positive for the endosulfan residues. Their ages were ranged between 14 to 55 years with a mean concentration of $0.21 \mathrm{mg} \cdot \mathrm{kg}^{-1}$. While, remaining 9 volunteers (45\%) were females having ages between 27 to 39 years with a mean concentration of $0.16 \mathrm{mg} \cdot \mathrm{kg}^{-1}$. Only one blood sample of male volunteer was found to be positive for $p, p$ '- $D D T$ residues with age of 55 years and mean concentration of $0.17 \mathrm{mg} \cdot \mathrm{kg}^{-1}$. Whereas, no blood samples of any female volunteer of Hyderabad district were found to be positive for $p, p$ '-DDT residues. Out of total 3 volunteers, parathion residues were found in 2 male volunteers $(67 \%)$ of ages 43 and 54 years with a mean concentration of $0.13 \mathrm{mg} \cdot \mathrm{kg}^{-1}$, and 1 female volunteer of age 37 years with a concentration of 0.11 $\mathrm{mg} \cdot \mathrm{kg}^{-1}$. Out of the total 23 volunteers from Mirpurkhas district who had residues of chlorpyrifos, 17 volunteers (74\%) were males with ages between 26 to 67 years and 6 volunteers $(26 \%)$ were females of ages between 30 to 45 years with mean concentrations of 0.21 and 0.17 $\mathrm{mg} \cdot \mathrm{kg}^{-1}$, respectively. While from total 16 volunteers who found to be positive for endosulfan residues, 9 volunteers $(56 \%)$ were males and 7 volunteers $(44 \%)$ were females of ages between 18 to 59 and 17 to 49 years with mean concentrations of 0.28 and $0.18 \mathrm{mg} \cdot \mathrm{kg}^{-1}$, respectively. Nor any blood sample of female volunteers was found to be contaminated with the residues of $p, p$ '-DDT in Mirpurkhas district as well, whereas 2 male volunteers of ages 34 and 61 years had residues of $p, p^{\prime}-D D T$ in their blood samples with a mean concentration of $0.17 \mathrm{mg} \cdot \mathrm{kg}^{-1}$. The blood samples of 3 male volunteers $(60 \%)$ out of total 5 were found to be positive for parathion residues. Their ages were ranged between 37 to 48 years with a mean concentration of $0.25 \mathrm{mg} \cdot \mathrm{kg}^{-1}$. While remaining 2 volunteers $(40 \%)$ were females of ages 49 and 53 years with a mean concentration of $0.18 \mathrm{mg} \cdot \mathrm{kg}^{-1}$.

The data in Table 6 shows the mean concentrations and ranges of detected pesticide residues based on the gender of non-agro professional volunteers. Out of total 5 
Table 4. Number of residue detected non-agro professional volunteers with their years of exposure, and mean concentrations of pesticide residues found in their blood samples.

\begin{tabular}{|c|c|c|c|c|}
\hline \multirow{2}{*}{ Location } & \multirow{2}{*}{ No. with residues detected } & \multicolumn{3}{|c|}{ Number of volunteers ( ${ }^{*}$ mean pesticide concentration, $\mathrm{mg} \cdot \mathrm{kg}^{-1}$ ) } \\
\hline & & Chlorpyrifos & Endosulfan & $p, p^{\prime}-D D T$ \\
\hline Hyderabad & 09 & $05(0.10)$ & $04(0.14)$ & $00(0.0)$ \\
\hline Mirpurkhas & 04 & $02(0.08)$ & $01(0.11)$ & $01(0.06)$ \\
\hline
\end{tabular}

${ }^{*}$ Standard deviation was below $5 \%$ from three replicate analyses of pesticide residues in the analyzed blood samples.

Table 5. Mean concentrations and range of detected pesticide residues based on the gender of agro professional volunteers.

\begin{tabular}{|c|c|c|c|c|c|}
\hline \multirow{2}{*}{ Location } & \multirow{2}{*}{ Pesticides detected \& Gender } & \multirow{2}{*}{ No. of volunteers } & \multirow{2}{*}{ Age range } & \multicolumn{2}{|c|}{ Residue concentrations $\left(\mathrm{mg} \cdot \mathrm{kg}^{-1}\right)$} \\
\hline & & & & Range & Mean $^{*}$ \\
\hline & Chlorpyrifos & & & & \\
\hline \multirow[t]{12}{*}{ Hyderabad } & M & 28 & $16-45$ & $0.04-0.31$ & 0.17 \\
\hline & $\mathrm{F}$ & 07 & $22-51$ & $0.02-0.28$ & 0.15 \\
\hline & Endosulfan & & & & \\
\hline & M & 11 & $14-55$ & $0.08-0.35$ & 0.21 \\
\hline & $\mathrm{F}$ & 09 & $27-39$ & $0.05-0.28$ & 0.16 \\
\hline & $p, p^{\prime}-D D T$ & & & & \\
\hline & M & 01 & 55 & 0.17 & 0.17 \\
\hline & $\mathrm{F}$ & - & - & - & - \\
\hline & Parathion & & & & \\
\hline & M & 02 & $43-54$ & $0.09-0.18$ & 0.13 \\
\hline & $\mathrm{F}$ & 01 & 37 & 0.11 & 0.11 \\
\hline & Chlorpyrifos & & & & \\
\hline \multirow[t]{11}{*}{ Mirpurkhas } & M & 17 & $26-67$ & $0.05-0.41$ & 0.21 \\
\hline & $\mathrm{F}$ & 06 & $30-45$ & $0.03-0.36$ & 0.17 \\
\hline & Endosulfan & & & & \\
\hline & M & 09 & $18-59$ & $0.06-0.44$ & 0.28 \\
\hline & $\mathrm{F}$ & 07 & $17-49$ & $0.08-0.34$ & 0.18 \\
\hline & $p, p^{\prime}-D D T$ & & & & \\
\hline & M & 02 & $34-61$ & $0.14-0.20$ & 0.17 \\
\hline & $\mathrm{F}$ & - & - & - & - \\
\hline & Parathion & & & & \\
\hline & M & 03 & $37-48$ & $0.15-0.34$ & 0.25 \\
\hline & $\mathrm{F}$ & 02 & $49-53$ & $0.09-0.28$ & 0.18 \\
\hline
\end{tabular}

*Standard deviation was below $5 \%$ from three replicate analyses of pesticide residues in the analyzed blood samples.

Table 6. Mean concentrations and range of detected pesticide residues based on the gender of non-agro professional volunteers.

\begin{tabular}{|c|c|c|c|c|c|}
\hline \multirow{2}{*}{ Location } & \multirow{2}{*}{ Pesticides detected \& Gender } & \multirow{2}{*}{ No. of volunteers } & \multirow{2}{*}{ Age range } & \multicolumn{2}{|c|}{ Residue concentrations $\left(\mathrm{mg} \cdot \mathrm{kg}^{-1}\right)$} \\
\hline & & & & Range & Mean ${ }^{*}$ \\
\hline \multirow{6}{*}{ Hyderabad } & Chlorpyrifos & & & & \\
\hline & $\mathrm{M}$ & 04 & $24-62$ & $0.04-0.11$ & 0.07 \\
\hline & $\mathrm{F}$ & 01 & 45 & 0.03 & 0.03 \\
\hline & Endosulfan & & & & \\
\hline & M & 02 & $17-43$ & $0.08-0.13$ & 0.10 \\
\hline & $\mathrm{F}$ & 02 & $44-56$ & $0.05-0.17$ & 0.11 \\
\hline
\end{tabular}


Continued

\begin{tabular}{|c|c|c|c|c|c|}
\hline & Chlorpyrifos & & & & \\
\hline \multirow[t]{8}{*}{ Mirpurkhas } & M & 02 & $36-49$ & $0.06-0.10$ & 0.08 \\
\hline & $\mathrm{F}$ & - & - & - & - \\
\hline & Endosulfan & & & & \\
\hline & M & - & - & - & - \\
\hline & $\mathrm{F}$ & 01 & 35 & 0.11 & 0.11 \\
\hline & $p, p^{\prime}-D D T$ & & & & \\
\hline & M & 01 & 58 & 0.06 & 0.06 \\
\hline & $\mathrm{F}$ & - & - & - & - \\
\hline
\end{tabular}

*Standard deviation was below $5 \%$ from three replicate analyses of pesticide residues in the analyzed blood samples.

volunteers from Hyderabad district, 4 volunteers (80\%) were males of ages between 24 to 62 years and 1 volunteer $(20 \%)$ was female of age 45 years found to contained residues of chlorpyrifos in their blood samples with mean concentrations of 0.07 and $0.03 \mathrm{mg} \cdot \mathrm{kg}^{-1}$, respectively. Out of total 4 volunteers who were found to be positive for the residues of endosulfan in their blood samples, 2 volunteers $(50 \%)$ were males of ages 17 and 43 years and another 2 volunteers $(50 \%)$ were females of ages 44 and 56 years with mean concentrations of 0.10 and $0.11 \mathrm{mg} \cdot \mathrm{kg}^{-1}$, respectively. In Mirpurkhas district, chlorpyrifos was detected in the blood samples of 2 male volunteers of ages 36 and 49 years with a mean concentration of $0.08 \mathrm{mg} \cdot \mathrm{kg}^{-1}$. The residues of endosulfan were detected in only one female volunteer of age 35 years with a concentration of $0.11 \mathrm{mg} \cdot \mathrm{kg}^{-1}$. Whereas, no any blood sample of male volunteers from Mirpurkhas district was found to be positive for endosulfan residues. In only one male volunteer of age 58 years the residues of $p, p^{\prime}-D D T$ were detected with a concentration of 0.06 $\mathrm{mg} \cdot \mathrm{kg}^{-1}$, while no any blood sample of female volunteers was found to be contaminated with the residues of $p, p^{\prime}-D D T$.

The pesticides detected in the blood samples of volunteers selected for this study are classified as insecticides, generally used by the farm workers to control different kinds of pests to protect their crops. The pattern showed by the two populations (Hyderabad and Mirpurkhas) was found to be almost similar. This may be due to the same climatic conditions and farming activities. Chlorpyrifos and endosulfan were the pesticides detected in most of the samples taken from both districts. Out of total 104 agro professional volunteers who found to be contaminated with different pesticide residues in their blood samples, the residues of chlorpyrifos were detected in 58 volunteers $(56 \%)$, while residues of endosulfan were detected in 36 volunteers (35\%). Out of total 13 non-agro professional volunteers who had pesticide residues in their blood samples, the residues of chlorpyrifos were detected in 7 volunteers (54\%); while, residues endosul- fan were detected in 5 volunteers (38\%). The representative chromatograms of blood samples containing residues of chlorpyrifos and endosulfan with their respective mass spectrums have been shown in Figure 3. Chlorpyrifos is an organophosphate (OPs) insecticide. It is moderately persistent and toxic in nature and suspected endocrine disruptor. It has found to be very effective against fly larvae, cabbage root fly and aphids. Because of its most widely used in homes against mosquito, cockroaches and termites it may be one reason of exposure for the nonagro professional volunteers. On the other hand, endosulfan is an organochlorine insecticide and acts as a poison to a spacious range of mites and insects on contact and as a stomach acaricide. Endosulfan has become known as an extremely controversial agrichemical by reason of its function as an endocrine disruptor, acute toxicity, and bioaccumulation potential. The technical grade endosulfan is a mixture of $\alpha$ and $\beta$ isomers in the ratio of 7:3, respectively. Comparatively, $\alpha$ isomer of endosulfan insecticide has been found to be three times more toxic than the $\beta$ isomer. It has been noticed during data collection about the clinical history of agro professional volunteers, most of the volunteers (who had pesticide residues in their blood samples) complained of vomiting, diarrhea, respiratory depression, productive cough, loss of consciousness, tingling or creeping on skin, severe headache, nausea and general body weakness or tiredness, which are the signs and symptoms of chlorpyrifos and endosulfan poisoning. Because of deficiencies in schooling, knowledge and broad information regarding the application of pesticides from government associations/activities in these regions, farm workers are suffering and getting unwell outcomes of pesticides during inappropriate usage, discarding and predominantly when they are not sheltered with special protecting equipments (gloves, rubber boots, safety goggles, masks, overalls with long sleeves etc.). The presence of pesticide residues in volunteers (non-agro professionals) is also very alarming and indicative of environmental exposure. After studying various other factors it is assumed that the 


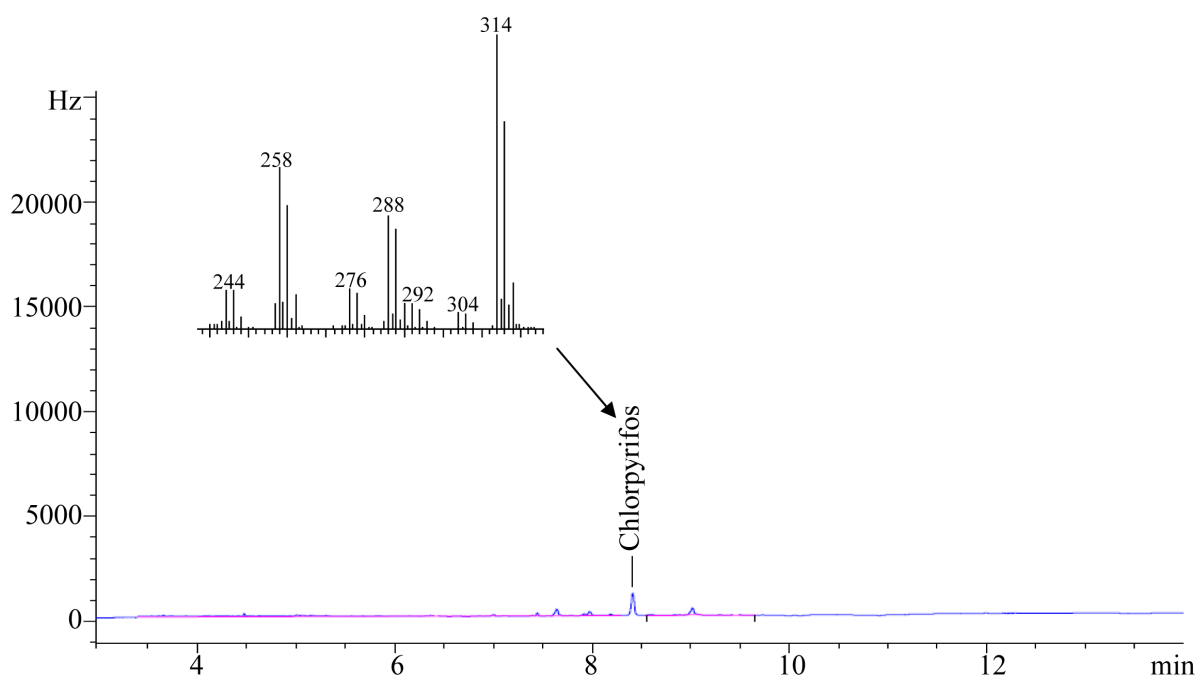

(a)

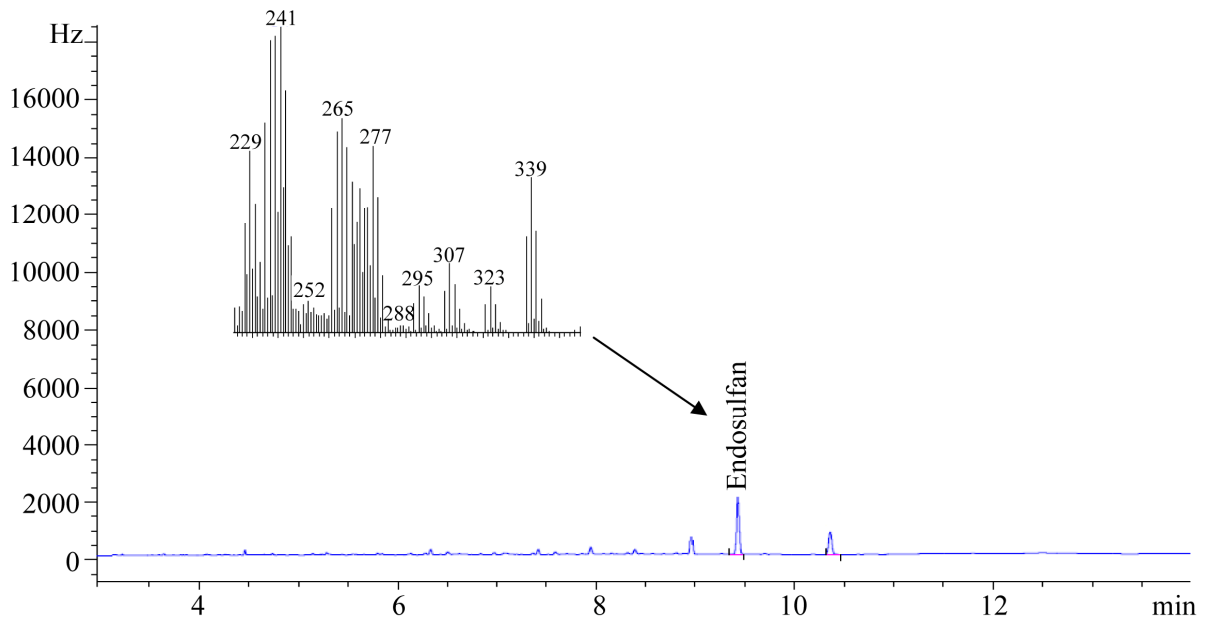

(b)

Figure 3. Representative chromatograms of blood samples containing chlorpyrifos (a) and endosulfan (b) with their confirmative main ion fragments shown in mass spectrum.

presence of chlorpyrifos and endosulfan residues in the blood of non-agro professional volunteers may be due to the massive use of these pesticides since last couple of decades, or may be other potential sources involved such as impurity of other pesticides or the direct use of chlorpyrifos and endosulfan as pesticides. Based on gender, we observed prevalence between males rather than females of both populations as shown in Table 6, but residue levels did not show any statistically significant difference.

In conclusion, the results of our study will form part of an up-to-date report on the contamination level of Hyderabad and Mirpurkhas regions including all kinds of populations of different socioeconomic characteristics, which will make it promising to identify the sources and trends of this contamination. Our study has shown that the volunteers monitored from both groups (agro and non-agro professionals) have been occupationally and environmentally exposed due to the excessive use of insecticides for pest control in their areas of cultivations. There is a need to revitalize the pesticide regulation in view of the types of insecticides commonly used and the residues detected in their blood. From this study, it is also concluded that the existence of chlorpyrifos and endosulfan with higher frequencies are being hauled the entire population towards numerous health hazards, so for now, the global restrictions for the use of these pesticides should be observed in Pakistan.

\section{Acknowledgements}

The authors would like to thank National Centre of Excellence in Analytical Chemistry, University of Sindh Jamshoro Pakistan and Pakistan Agriculture Research Council (PARC), for the financial support to carry out 
the present research work.

\section{REFERENCES}

[1] H. B. Mathur, H. C. Agarwal, S. Johnson, et al., "Analysis of Pesticide Residues in Blood Samples from Villages of Punjab," CSE/PML/PR-21, 2005.

[2] J. Rothlein, D. Rohlman, M. Lasarev, et al., "Organophosphate Pesticide Exposure and Neurobehavioral Performance in Agricultural and Non-Agricultural Hispanic Workers," Environmental Health Perspectives, Vol. 114, No. 5, 2006, pp. 691-696. doi:10.1289/ehp.8182

[3] Y. Latif, S. T. H. Sherazi and M. I. Bhanger, "Assessment of Pesticide Residues in Some Fruits Using Gas Chromatography Coupled with Micro Electron Capture Detector," Pakistan Journal of Analytical and Environmental Chemistry, Vol. 1-2, 2011, pp. 76-87.

[4] B. D. Banerjee, V. Seth, A. Bhattacharya, et al., "Biochemical Effects of Some Pesticides on Lipid Peroxidation and Free-Radical Scavengers," Toxicology Letters, Vol. 107, No. 1-3, 1999, pp. 33-47. doi:10.1016/S0378-4274(99)00029-6

[5] M. Iscan, T. Coban, I. Cok, et al., "The Organochlorine Pesticide Residues and Antioxidant Enzyme Activities in Human Breast Tumors: Is There Any Association?" Breast Cancer Research and Treatment, Vol. 72, No. 2, 2002, pp. 173-182. doi:10.1023/A:1014828705281

[6] M. S. Wolff, A. Zeleniuch-Jacquotte, N. Dubin, et al., "Risk of Breast Cancer and Organochlorine Exposure," Cancer Epidemiology Biomarkers and Preventation, Vol. 9, No. 3, 2000, pp. 271-277.

[7] J. M. Safi, "Association between Chronic Exposure to
Pesticides and Recorded Cases of Human Malignancy in Gaza Governorates (1990-1999)," Science of the Total Environment, Vol. 284, No. 1-3, 2002, pp. 75-84. doi:10.1016/S0048-9697(01)00868-3

[8] M. A. Azmi, S. N. H. Naqvi, M. A. Azmi, et al., "Effect of Pesticide Residues on Health and Different Enzyme Levels in the Blood of Farm Workers from Gadap (Rural Area) Karachi, Pakistan," Chemosphere, Vol. 64, No. 10, 2006, pp. 1739-1744.

doi:10.1016/j.chemosphere.2006.01.016

[9] Y. Latif, S. T. H, Sherazi and M. I. Bhanger, "Assessment of Pesticide Residues in Commonly Used Vegetables in Hyderabad, Pakistan," Ecotoxicology and Environmental Safety, Vol. 74, No. 8, 2011, pp. 2299-2303. doi:10.1016/j.ecoenv.2011.07.030

[10] Y. Latif, S. T. H. Sherazi and M. I. Bhanger, "Monitoring of Pesticide Residues in Commonly Used Fruits in Hyderabad Region, Pakistan," American Journal of Analytical Chemistry, Vol. 2, No. 8, 2011, pp. 46-52. doi:10.4236/ajac.2011.228123

[11] Codex Alimentarius Commission (CODEX), "Report of the Twenty-Seven Session," Geneva, 28 June-3 July 2004.

[12] M. A. Azmi, S. N. H. Naqvi and M. A. Azmi, "Pesticide Residue in the Blood of Rural Population from Gadap, Karachi and Related Health Hazards," Journal of Experimental Zoology India, Vol. 8, 2005, pp. 343-351.

[13] S. Cruz, C. Lino and M. I. Silveira, "Evaluation of Organochlorine Pesticide Residues in Human Serum from an Urban and Two Rural Populations in Portugal," Science of the Total Environment, Vol. 317, No. 1-3, 2003, pp. 23-35. doi:10.1016/S0048-9697(03)00334-6 